\title{
Identification and characterization of lysine-rich proteins and starch biosynthesis genes in the opaque2 mutant by transcriptional and proteomic analysis
}

Mo Jia ${ }^{1}$, Hao Wu' ${ }^{1}$ Kasi L Clay ${ }^{1}$, Rudolf Jung², Brian A Larkins ${ }^{3}$ and Bryan C Gibbon ${ }^{1 *}$

\begin{abstract}
Background: The opaque2 mutant is valuable for producing maize varieties with enhanced nutritional value. However, the exact mechanisms by which it improves protein quality and creates a soft endosperm texture are unclear. Given the importance of improving nutritional quality in grain crops, a better understanding of the physiological basis for these traits is necessary.
\end{abstract}

Results: In this study, we combined transcript profiling and proteomic analysis to better understand which genes and proteins are altered by opaque2 in the W64A inbred line. These analyses showed that the accumulation of some lysine-rich proteins, such as sorbitol dehydrogenase and glyceraldehyde3-phosphate dehydrogenase, was increased in mature kernels and may contribute substantially to the lysine content of opaque2 endosperm. Some defense proteins such as beta-glucosidase aggregating factor were strongly down regulated and may be regulated directly by opaque2. The mutant also had altered expression of a number of starch biosynthesis genes and this was associated with a more highly crystalline starch.

Conclusions: The results of these studies revealed specific target genes that can be investigated to further improve nutritional quality and agronomic performance of high lysine maize lines, particularly those based on the presence of the opaque2 mutation. Alteration of amylopectin branching patterns in opaque2 starch could contribute to generation of the soft, starchy endosperm.

Keywords: Opaque endosperm, Opaque2, Quality protein maize, Starch biosynthesis, Protein quality

\section{Background}

Maize is a major food and feed crop, and the acreage devoted to maize cultivation is expected to increase significantly over the next several decades due to greater demand for the grain [1]. The majority of the maize crop is used to feed livestock, but in substantial parts of Central America, Africa and Asia, maize is the primary food staple for humans. In order to maximize land productivity, the nutritional quality of crops should be one of the factors considered, along with water and nitrogen

\footnotetext{
* Correspondence: bryan_gibbon@baylor.edu

'Department of Biology, Baylor University, One Bear place \#97388, Waco, TX 76798, USA

Full list of author information is available at the end of the article
}

use efficiency, yield, pest resistance and other determinants of crop productivity [2].

Maize protein is deficient in the essential amino acids lysine and tryptophan, which limits its value for monogastric animals. Therefore, for the past several decades there have been efforts to create maize lines with increased essential amino acid content. In the 1960s the research groups of Mertz and Nelson at Purdue University identified several mutants with increased lysine content, opaque2 (o2) and floury2 in particular, had substantially higher essential amino acid content $[3,4]$. However, these mutations result in a soft, chalky endosperm phenotype that is not suitable for agronomic production because of increased susceptibility to insect and fungal pests and decreased yields $[5,6]$. The $O 2$ gene was found

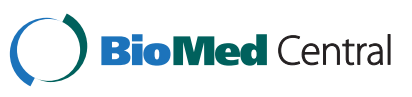


to encode a b-zip transcription factor [7] that regulates expression of several genes in the endosperm, notably those encoding the $22 \mathrm{kDa} \alpha$-zein storage proteins [8]. The substantial reduction in synthesis of $\alpha$-zeins results in smaller, less numerous protein bodies and a concomitant increase in non-zein endosperm proteins [3]. These changes in protein accumulation result in an endosperm that has nearly twice the lysine and tryptophan content of wild-type maize [3], which substantially improves its value for monogastric animals [9]. Therefore, breeders began recurrent selection of $o 2$ lines with high lysine and a hard endosperm, called Quality Protein Maize [10].

Recently, considerable progress has been made developing maize lines and optimizing amino acid balance using transgenic [11-13] and conventional breeding approaches through marker-assisted selection [14,15]. The most successful transgenic strategies have been specific knock down of zein storage protein or lysine catabolism gene expression with RNA interference (RNAi) approaches [11-13,16]. Reduced synthesis of the lysinepoor zein proteins and compensatory increases in other proteins dramatically improves the nutritional quality of the grain. The underlying mechanism for rebalancing amino acid content for both $o 2$ and RNAi is unclear, although it depends on reduced synthesis of the zein storage proteins and a compensatory increase in non-zein protein content [17]. Generally, the total protein content is only slightly depressed relative to wild type kernels $[12,17,18]$, and knocking down 19- and 22-kDa $\alpha$-zeins in high or low protein lines by RNAi only modestly changes total protein content from the parental levels, suggesting that total protein content is under genetic control [17]. It is possible that competition between mRNA transcripts for ribosomes is responsible for the final protein composition, as has been proposed for soybean [19].

Despite these advances in developing maize lines with higher nutritional value, the underlying physiological and molecular mechanisms that cause soft kernels is still not well understood. Several studies have investigated the changes in transcriptional patterns caused by the $o 2$ mutation [20-23]. Consistent observations among them point to pleotropic changes in gene expression, but it has been difficult to identify physiological pathways that explain the soft kernel phenotype and changes in protein synthesis that contribute to the improved amino acid composition of the endosperm. Genes related to endoplasmic reticulum (ER) stress responses are consistently up regulated in opaque mutants [22], as are many genes in the glycolytic pathway and others that are typically associated with physiological responses to anoxic stress, such as alcohol dehydrogenase and sorbitol dehydrogenase $[21,22,24]$, but their roles in the expression of the opaque phenotype are not clear. Proteomic analysis of protein accumulation during $o 2$ development is generally consistent with the pattern of gene expression observed by microarray analysis [25].

In this study we analyzed gene expression in 02 endosperm using an amplified fragment length polymorphism (AFLP)-based approach that is open-ended and does not depend on known or predicted gene sequences. We also performed a proteomic analysis of mature seeds to identify specific proteins that contribute disproportionately to the increased lysine and tryptophan content in order to relate these more abundant gene products to gene expression in maturing endosperm. In addition to confirming overall gene expression patterns previously described for $o 2$ mutants, we identified a number of other differences in mRNA transcript levels compared to wild type endosperms. Several gene products related to defense responses were also substantially down regulated in $o 2$ endosperm, which could further explain its greater susceptibility to ear rots and insect pests. Expression of starch biosynthetic genes was altered in $o 2$ and was associated with changes in starch granule structure. Furthermore, analysis of protein accumulation in mature seeds revealed a few lysine-rich proteins that were substantially more abundant in $o 2$ endosperm. These changes could explain a significant fraction of the increased lysine content in W64Ao2. How changes in gene expression, protein content and starch structure contribute to the development of opaque endosperm is discussed.

\section{Results and discussion}

\section{Overview of transcript profiling}

To systematically compare gene expression patterns between W64A + and W64Ao2 at the most metabolically active stage of endosperm development, transcript profiling was performed at Curagen Corp. (New Haven, CT) by GeneCalling ${ }^{\text {TM }}$ [26] at 22 days after pollination (DAP). The GeneCalling ${ }^{\mathrm{TM}}$ approach does not rely on a priori knowledge of gene sequences and can therefore identify expression differences for genes that are not present in sequence databases. cDNA fragments were generated with 47 different pairs of restriction enzymes, and the expression levels of the corresponding gene fragments were compared. A total of 470 putative genes were identified as differentially expressed in W64A + and W64Ao2 by the GeneCalling ${ }^{\text {TM }}$ software using a t-test. The sequence of a subset of the differentially expressed gene fragments was confirmed by oligonucleotide competition, "poisoning", with an unlabeled gene-specific primer or by cloning and sequencing the fragments if poisoning failed. The identities of 274 gene fragments ranging from 50 to $500 \mathrm{bp}$ were confirmed and represented a total of 151 gene products. Further characterization of these genes was obtained by BLASTN and BLASTX analyses against Genbank and Maize Genome Sequence databases (http:// www.maizesequence.org). The molecular functions and 
biological processes were annotated using the gene ontology database (G.O.; http://www.geneontology.org) and classification of their molecular functions and biological processes are illustrated in Figure 1. A comprehensive table of differentially expressed genes and their properties is provided in Additional file 1: Table S1. Twenty-six distinct biological functions were affected in W64Ao2, including carbohydrate metabolism and stress responses, which are associated with the altered endosperm phenotype of the $o 2$ mutant. Specifically, 70 genes corresponding to 23 functional groups were up regulated and 81 gene fragments belonging to 16 groups were down regulated in $o 2$.

\section{GO functional classes of up regulated and down regulated genes}

As expected, a large number of down regulated genes have a molecular function associated with nutrient reservoir activity (Figure 1), which is due to the accumulation of several 19- and 22-kD $\alpha$-zein genes and the 27-kD $\gamma$-zein being significantly reduced in $o 2$. These proteins are encoded by large gene families with highly conserved sequences and are well-characterized targets of $\mathrm{O} 2 \mathrm{regu}-$ lation [27,28]. Reduction in nutrient reservoir gene function in $o 2$ is followed by catalytic activity (23\%), structural molecule activity (8\%), protein binding (8\%), DNA binding (6\%), transporter activity (4\%) and other minor categories (4\%), such as ion binding and enzyme regulator activity. Among biological processes, 34\% of the down regulated genes participate in the secretory pathway, which may reflect a response to the reduced accumulation of the ER-resident zein storage proteins. Other down regulated functional categories include physiological defense (11\%), metabolism (8\%), lipid metabolism (7\%), transport (4\%), translation (4\%) and other (17\%). There are $20 \%$ and $16 \%$ of the genes with unknown molecular function and biological process, respectively.

For genes that are up regulated in $o 2$, only a small proportion have the function of nutrient reservoir activity (6\%). Instead, the largest proportion of the up regulated genes have catalytic activities (23\%), followed by DNA binding (13\%), protein binding (7\%), structural molecule activity (4\%) and other (15\%). This is consistent with metabolism being the most affected biological function (19\%), followed by secretion (14\%), protein folding (6\%), transcription (6\%), transposition (6\%), and physiological defense response (4\%). Of the up regulated genes, 32\% could not be assigned a molecular function and 34\% could not be assigned to a biological process.

\section{Genes down regulated in 02}

As expected, members of the zein gene family were significantly down regulated in $o 2(19 \mathrm{kDa}$ and $22 \mathrm{kDa}$ $\alpha$-zeins and $27 \mathrm{kDa} \gamma$-zein). There were a few zein genes with increased expression in 02 . However, this method of analyzing transcripts is very sensitive to allelic differences, and the up regulated zein genes may represent
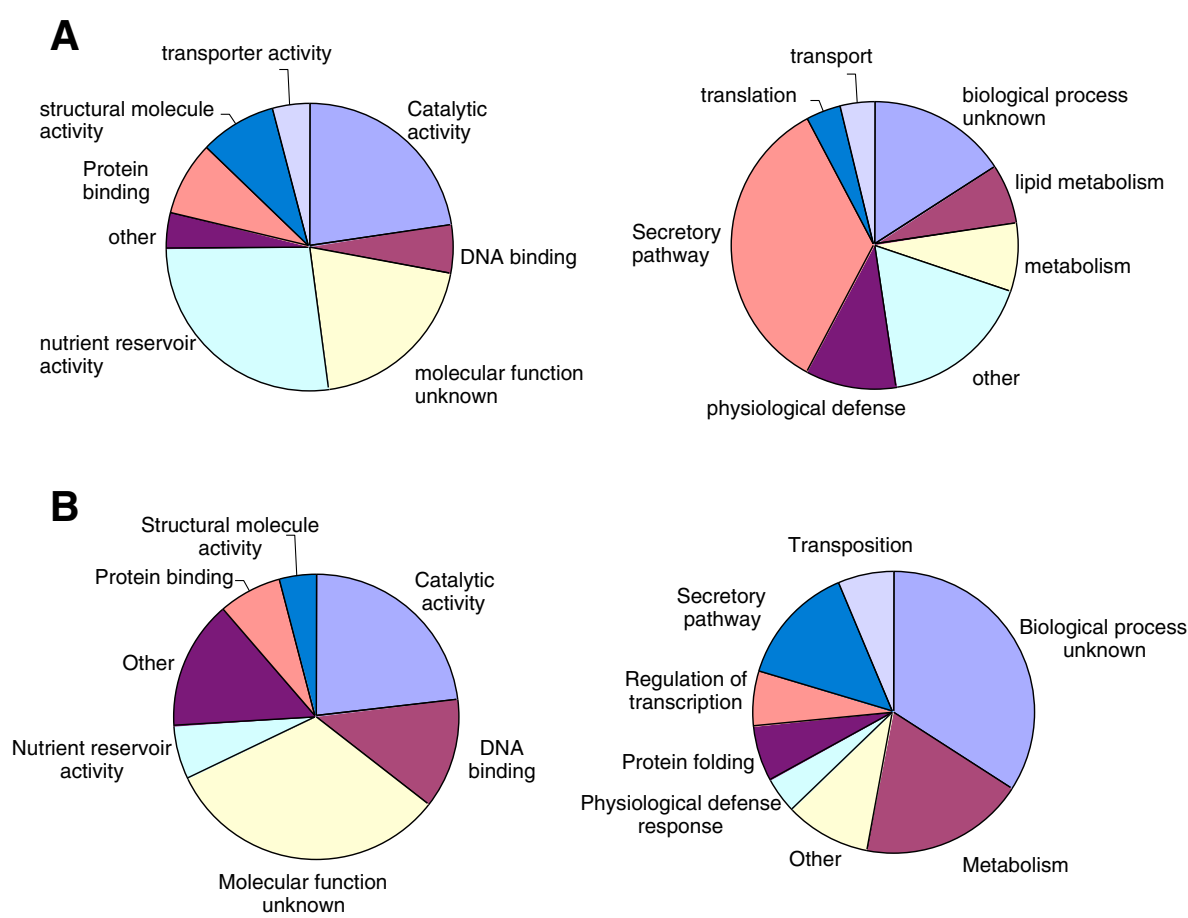

Figure 1 GO classification for genes with altered expression in o2. Genes were assigned to GO molecular function (A) and biological process (B). The plots on the left are genes down regulated in 02 and the plots on the right are genes up regulated in 02 . 
such alleles. Several genes that are reported to participate in defense responses to biotic and abiotic stresses were also significantly down regulated in $o 2$, such as a ribosome-inactivating protein (RIP) b-32, which has a defensive role against pathogens and viruses and a wellknown target of $\mathrm{O} 2$ regulation in maize [29,30]. A betaglucosidase aggregating factor-like protein (BGAF) was also strongly down regulated; such proteins are reported to be involved in defense against pathogens and herbivores [31,32]. The BGAF-like protein may be a particularly interesting gene to study further because it has an $\mathrm{O} 2$ consensus binding sequence $[24,33]$ at $-227 \mathrm{nt}$ from the predicted transcription start. However, there were several other defense-related transcripts that were down regulated to a lesser extent, subtilisin-chymotrypsin inhibitor CI-1B (CI-1B), which responds to wounding [34], flower-specific gamma-thionin (defensin SD2), which is toxic to animal cells and defends against parasites [35], and basal layer antifungal protein2 (BAP2). It is possible that the high sensitivity of $o 2$ to fungal and insect pests is due to the synergistic effect of reducing both b-32 and BGAF protein levels in $o 2$ endosperm.

Several ribosomal proteins, such as the $40 \mathrm{~S}$ subunit protein S3a and the 60S ribosomal subunit protein L193 , and the 18S RNA gene, the structural RNA for the small subunit of eukaryotic cytoplasmic ribosomes, were all down regulated in 02 . Some of these changes in ribosomal constituents may be cellular responses to the changes in the overall mRNA pool, which lacks the abundant ER-targeted $\alpha$-zein mRNAs in $o 2$. Other down regulated transcripts included NAC (NAM, ATAF, and CUC transcription factor) domain-containing protein 48 , which is predicted to function as a plant specific transcription factor involved in a variety of developmental events, as well as in biotic and abiotic stress responses [36]. Genes that function in signal transduction, such as YT521-B-like family protein, glutathione S-transferase GST 31, protein FAR-RED IMPAIRED RESPONSE 1, also showed decreased expression in 02 . The role of these transcription factors and signal transduction proteins have in the formation of the opaque phenotype, if any, is unclear.

Several genes that function in amino acid metabolism were also down regulated, including tryptophan aminotransferase (TA1) and ketol-acid reductoisomerase which catalyzes two steps of the biosynthetic pathway of the branched-chain amino acids valine, leucine and isoleucine [37] and alanine-glyoxylate aminotransferase 2. Surprisingly, LKR-SDH1 is thought to be regulated by $\mathrm{O} 2$ [38], yet the transcript expression was not significantly different between W64A + and W64Ao2 and this may indicate that its expression is influenced by genetic background or environment. It may be the case that a large number of amino acid biosynthetic enzymes are regulated to some extent by $\mathrm{O} 2$. The yeast homolog of $\mathrm{O} 2$, the b-zip transcription factor GCN4 (General Control Non-derepressible 4), is known to induce the expression of a large number of amino acid biosynthetic genes in response to amino acid starvation [39] and gcn4 mutants can be complemented by expression of the maize $\mathrm{O} 2$ gene [40].

Several genes related to cell structure and development were down regulated in W64Ao2, including: katanin p60 ATPase which is involved in the regulation of microtubule dynamics [41] and regulates plant cell division and growth [42]; arabinogalactan protein (AGP), which serves as a marker of cellular identity and fate, and functions in plant vegetative growth and development as well as secondary cell wall thickening and programmed cell death [43]; brassinosteroid biosynthesis-like proteins, which are natural growth regulators required for post-embryonic growth [44]; and maternal effect embryo arrest 21 (MEE21), which regulates embryo development and maturation [45]. Although it is not known how such proteins influence the opaque phenotype, it is possible that they could cause changes in cellular organization that predispose the endosperm cells to develop the characteristic gaps between starch granules that is a hallmark of opaque endosperm.

\section{Genes up regulated in 02}

A number of genes encoding primary carbohydrate metabolism enzymes were up regulated in W64Ao2. Two enzymes of the glycolytic pathway were up regulated, cytosolic triosephosphate isomerase (TIM) and cytosolic phosphoglycerate kinase (PGK). Fructokinase-1, which functions at the entry point into glycolysis via the formation of glucose-6-phosphate and maintains the flux of carbon towards starch formation, was increased 1.85fold. Many of these changes in glycolytic enzyme expression and the up regulation of alcohol dehydrogenase 1 by 2.86 -fold were consistent with a hypoxic response. It has been shown that the maize endosperm is a highly anoxic environment compared to the embryo, and that this is likely to result in the shunting of carbon into starch rather than oil [46]. However, it is not clear why the 02 mutant would display increased hypoxic responses, and the proportion of starch in $o 2$ endosperm is essentially identical to wild type in the W64A background (not shown).

Enzymes involved in starch biosynthesis were increased in $o 2$, including granule-bound starch synthase I (GBSSI), which is required for the synthesis of amylose. Enzymes required for amylopectin synthesis were also up regulated, including pullulanase-type starch debranching enzyme1 (Zpu1), which hydrolyzes the $\alpha-1,6$-glucosic linkages of polyglucans, 1,4-alpha-glucan-branching enzyme 2 (BE2), which catalyzes the formation of $\alpha-1,6$ glucan and is required for amylopectin synthesis at the surface of the 
starch granule. Trehalose-6-phosphate synthase was also increased, which has been implicated in the redox activation of ADP-Glc phosphorylase, the enzyme that catalyzes the first committed step of starch synthesis $[47,48]$. Prior work has shown that the biochemical properties of starch are altered in opaque mutants [49], but the underlying mechanism is still not clear. The change in expression of one or more starch biosynthesis enzymes could result in the observed properties of $o 2 \mathrm{starch}$, although altering the expression or mutation of one starch biosynthetic enzyme can have complex effects on multiple enzyme activities.

Several proteins involved in the maintenance and folding of proteins in the ER were up regulated. The expression of the calcium-dependent protein chaperones, Calnexin, calreticulin2 and the chaperone DNA J2, were increased approximately two-fold in W64Ao2. The small cytoplasmic chaperones, $16.9 \mathrm{kDa}$ class I heat shock protein 3 and heat shock protein $18 \mathrm{c}$ were also up regulated. Other ER enzymes involved in the oxidation of cysteine to form disulfide bonds including protein disulfide isomerase (PDI) and ER Membrane-Localized Oxidoreductase 1 (ERO1) were increased [50]. These genes are related to the unfolded protein response and their up regulation is likely due to alteration of protein body structure in the ER [22].

Stress-response and defense genes up regulated in W64Ao2 included the following: alliin lyase 2 (alliinase) and cystatin 6 , which are part of the defense response against herbivores [51,52]; xylanase inhibitor protein 1 and glycine-aspartic acid-serine-leucine (GDSL)-motif lipase/hydrolase-like protein, both of which are involved in the defense against fungal pathogens $[53,54]$; and a $\mathrm{Pi}$ starvation-induced protein and an ABA-responsive $40 \mathrm{kDa}$ protein [55-57]. A MAP kinase was up regulated, as were several MAP kinase responsive genes. These include the respiratory burst oxidase protein, homolog $\mathrm{B}$ (RBOHB), and an inducible form of the NADPH oxidase, a downstream effector in the mitogen-activated protein kinase (MAPK) regulated signaling pathway that generates reactive oxygen species (ROS) and triggers innate immunity in response to various stresses [58]. Additionally, the WRKY transcription factor was up regulated, which is phosphorylated and activated by MAPKs in response to biotic and abiotic stresses [59]. These up regulated stress responses are unlikely to confer enhanced resistance to pests and most likely represent pleiotropic responses to mutation of $o 2$, because there is ample evidence that $o 2$ is much more susceptible to pests.

\section{Proteomic comparison of opaque 2 and wild type lines}

In order to detect differences in non-zein protein accumulation in W64Ao2 and wild type lines, we performed 2D SDS-PAGE analysis with equal amounts of non-zein proteins purified from mature endosperms using a borate extraction method [60]. Mature kernels were analyzed in order to determine if abundant non-zein proteins that contribute to increased lysine were consistent with their gene expression during endosperm development. After visualization and alignment of gels, 40 protein spots that were differentially resolved or showed altered accumulation levels were excised from gels for identification (Figure 2). Proteins of interest were identified by MALDI-TOF peptide mass mapping of trypsin digests of the protein spots. GBSSI, enolase 1, leguminlike protein, GAPDH, TIM and SDH showed increased accumulation in $o 2$, while enolase 2 and HSP3 showed no alteration in accumulation (Table 1). Many of the largest differences in protein accumulation were reflected in the transcript levels measured by transcript profiling

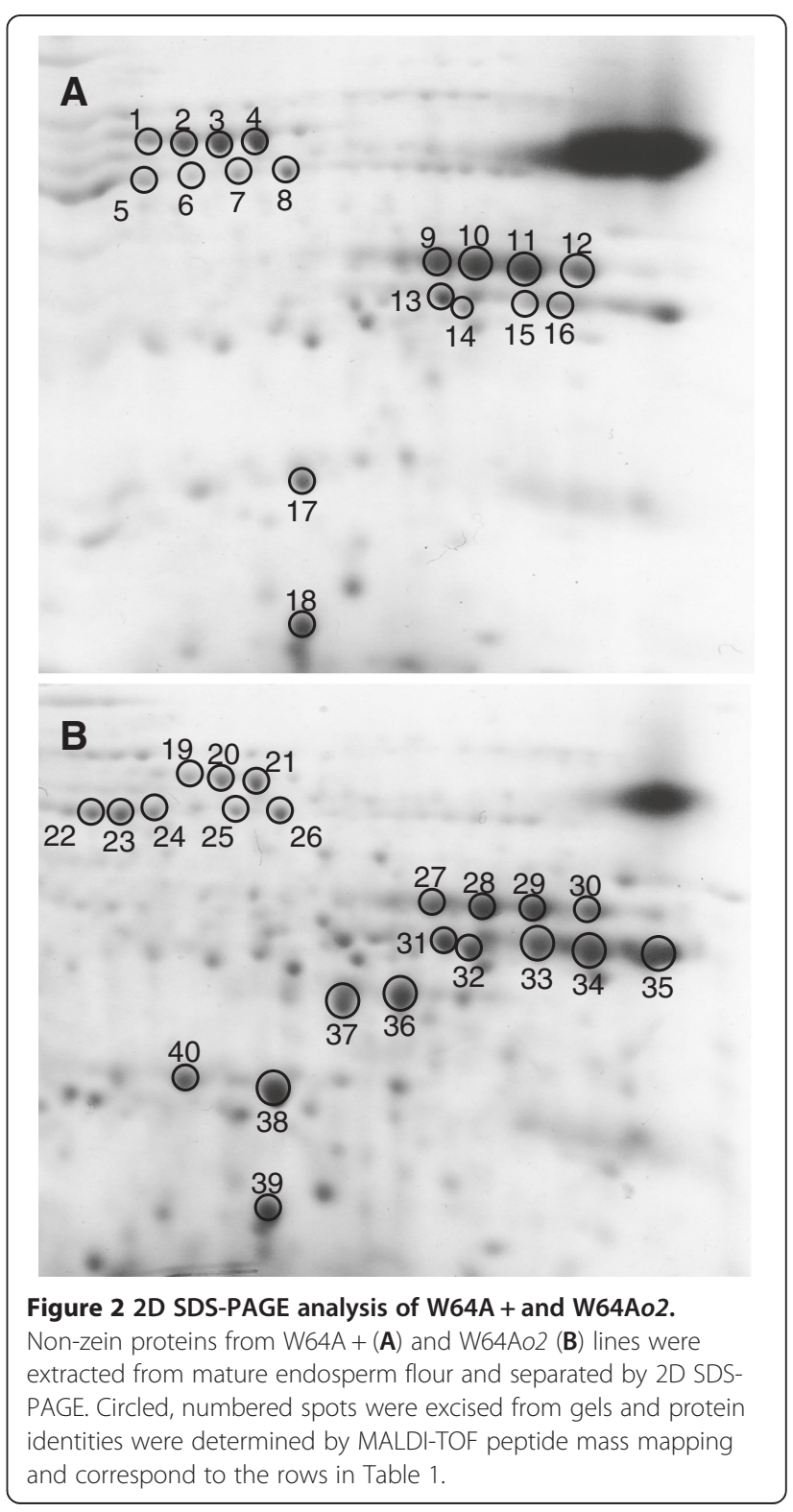


Table 1 Identity and expression differences of proteins separated by 2D SDS-page

\begin{tabular}{|c|c|c|c|}
\hline Spot & Genbank & Annotation & Fold-change \\
\hline 1 & P04713 & Granule-bound starch synthase 1 & \\
\hline 2 & P04713 & Granule-bound starch synthase 1 & \\
\hline 3 & P04713 & Granule-bound starch synthase 1 & \\
\hline 4 & P04713 & Granule-bound starch synthase 1 & \\
\hline 5 & NP_001105896 & enolase 1 & \\
\hline 6 & NP_001105896 & enolase 1 & \\
\hline 7 & NP_001105371 & enolase 2 & \\
\hline 8 & NP_001105371 & enolase 2 & \\
\hline 9 & BAB11045 & sorbitol dehydrogenase-like protein & \\
\hline 10 & BAB11045 & sorbitol dehydrogenase-like protein & \\
\hline 11 & BAB11045 & sorbitol dehydrogenase-like protein & \\
\hline 12 & BAB11045 & sorbitol dehydrogenase-like protein & \\
\hline 13 & ACG32147 & eukaryotic translation initiation factor 2 alpha & \\
\hline 14 & AAO63267 & Legumin-like protein, complete & \\
\hline 15 & Q43247 & Glyceraldehyde-3-phosphate dehydrogenase & \\
\hline 16 & Q43247 & Glyceraldehyde-3-phosphate dehydrogenase & \\
\hline 17 & NP_001140424 & triosephosphate isomerase & \\
\hline 18 & ACG35098 & $17.4 \mathrm{kDa}$ class I heat shock protein 3 & \\
\hline 19 & P04713 & Granule-bound starch synthase 1 & $-2.5^{1}$ \\
\hline 20 & P04713 & Granule-bound starch synthase 1 & -2.1 \\
\hline 21 & P04713 & Granule-bound starch synthase 1 & -1.5 \\
\hline 22 & NP_001105896 & enolase 1 & 1.3 \\
\hline 23 & NP_001105896 & enolase 1 & 1.2 \\
\hline 24 & NP_001105896 & enolase 1 & 1.1 \\
\hline 25 & NP_001105371 & enolase 2 & 1.1 \\
\hline 26 & NP_001105371 & enolase 2 & 1.3 \\
\hline 27 & BAB11045 & sorbitol dehydrogenase-like protein & -1.5 \\
\hline 28 & BAB11045 & sorbitol dehydrogenase-like protein & -1.2 \\
\hline 29 & BAB11045 & sorbitol dehydrogenase-like protein & -1.4 \\
\hline 30 & BAB11045 & sorbitol dehydrogenase-like protein & -1.2 \\
\hline 31 & ACG32147 & eukaryotic translation initiation factor 2 alpha & 1.2 \\
\hline 32 & AA063267 & Legumin-like protein, complete & 1.5 \\
\hline 33 & Q43247 & Glyceraldehyde-3-phosphate dehydrogenase & 1.7 \\
\hline 34 & Q43247 & Glyceraldehyde-3-phosphate dehydrogenase & 1.8 \\
\hline 35 & AAA87580 & Glyceroldehyde-3-phosphate dehydrogenase & 1.6 \\
\hline 36 & NP_001149440 & sorbitol dehydrogenase homolog1 & 2.7 \\
\hline 37 & ABA70761 & sorbitol dehydrogenase & 2.9 \\
\hline 38 & NP_001140424 & triosephosphate isomerase, cytosolic & 1.5 \\
\hline 39 & ACG35098 & 17.4 kDa class I heat shock protein 3 & 1.2 \\
\hline 40 & NP_001140424 & triosephosphate isomerase, cytosolic & 1.6 \\
\hline
\end{tabular}

${ }^{1}$ Bold values indicate significant difference by ANOVA $(p<0.05 ; n=3)$. 
at 22 DAP. The exceptions were GBSSI and enolase 1, which had inconsistent fold-changes in multiple studies [20-22]. This could be due to differences in genetic backgrounds of the lines analyzed or the different environments in which the materials were grown. However, in the W64A background the transcript profiling and proteomic data showed enolase 1 accumulation was higher in o2 (Figure 2). Notably, there was a significant increase $(\sim 1.8$-fold $)$ in the accumulation of GAPDH, which contains over $8 \%$ lysine, but was not found to be significantly different in transcript abundance in the transcript profiling data. Likewise there was a $>2.5$-fold increase in some SDH1 isoforms and this protein contains $4 \%$ lysine, which is lower than GAPDH, but nearly two-fold higher than the typical total lysine content of wild type maize endosperm. The increase in GAPDH and SDH1 could contribute significantly to the elevated level of lysine in W64Ao2, and the expression of these very abundant proteins may be associated with the expression of translation elongation factor 1A (EFIA), which is correlated with lysine content in maize endosperm but is not sufficient to explain the total increase in lysine content [61].

\section{Validation of gene expression}

Quantitative real-time polymerase chain reaction (qRTPCR) was performed for several genes encoding both up and down regulated transcripts in W64Ao2 to validate the results from the transcript profiling experiment with endosperms from both genotypes at 22 DAP. Retinoblastoma-related protein 1 (RRB1) was used as the reference gene, because it is consistently expressed in both genotypes (see Materials and Methods). The RIP gene, b-32, was chosen as a positive control for qRT$\mathrm{PCR}$, because it is known to be down regulated in 02 mutants [30]. Genes were selected based on the following categories: 1) genes with expression that was highly reduced in the $o 2$ mutant in the profiling experiment, such as proteosome regulatory subunit AAA-ATPase (AAA-ATPase), stem-specific protein (TSJT1), 16-kDa oleosin, CI-1B and BGAF, which had not been characterized in previous studies; 2) starch biosynthesis genes, such as Zpu1, starch branching enzyme IIb (BEIIb) and GBSSI; 3) genes related to carbohydrate metabolism that were changed in the transcript profiling or 2D SDSPAGE analysis, including GAPDH, sorbitol dehydrogenase 1 (SDH1), TIM, enolase 1 and PGK; and 4) other genes that showed changes in W64Ao2 according to profiling results, such as actin2, legumin1, 17.4 kDa class I heat shock protein 3 (HSP3) and LKR-SDH1.

The relative expression levels of transcripts among various samples in the qRT-PCR generally agreed with the profiling results (Pearson correlation coefficient $r=0.80$, ANOVA $\mathrm{p}<0.001$; Additional file 2: Figure S1).
However, in some cases the transcript fold-changes measured by Gene Calling were higher than those from qRT-PCR. The transcript level of the known O2regulated gene b-32 was significantly reduced in 02 by both transcript profiling and qRT-PCR (Figures 3A and $3 B)$, consistent with previous reports [20-22]. The transcript levels of BGAF, $16 \mathrm{kDa}$ oleosin, CI-1B, TSJT1 and AAA-ATPase were all significantly reduced in $o 2$, compared to W64A + by qRT-PCR (Figure 3B) and Gene Calling (Figure 3A and Additional file 1: Table S1). qRTPCR analysis also confirmed the expression of starch synthesis genes that were found to be up regulated in $o 2$ such as Zpu1 and BEIIb [20,22] (Figure 3). Although in the case of Zpu1, the increase was greater in the GeneCalling results (2.27-fold versus 1.55 -fold in qRT$\mathrm{PCR})$. These results indicate that the majority of changes

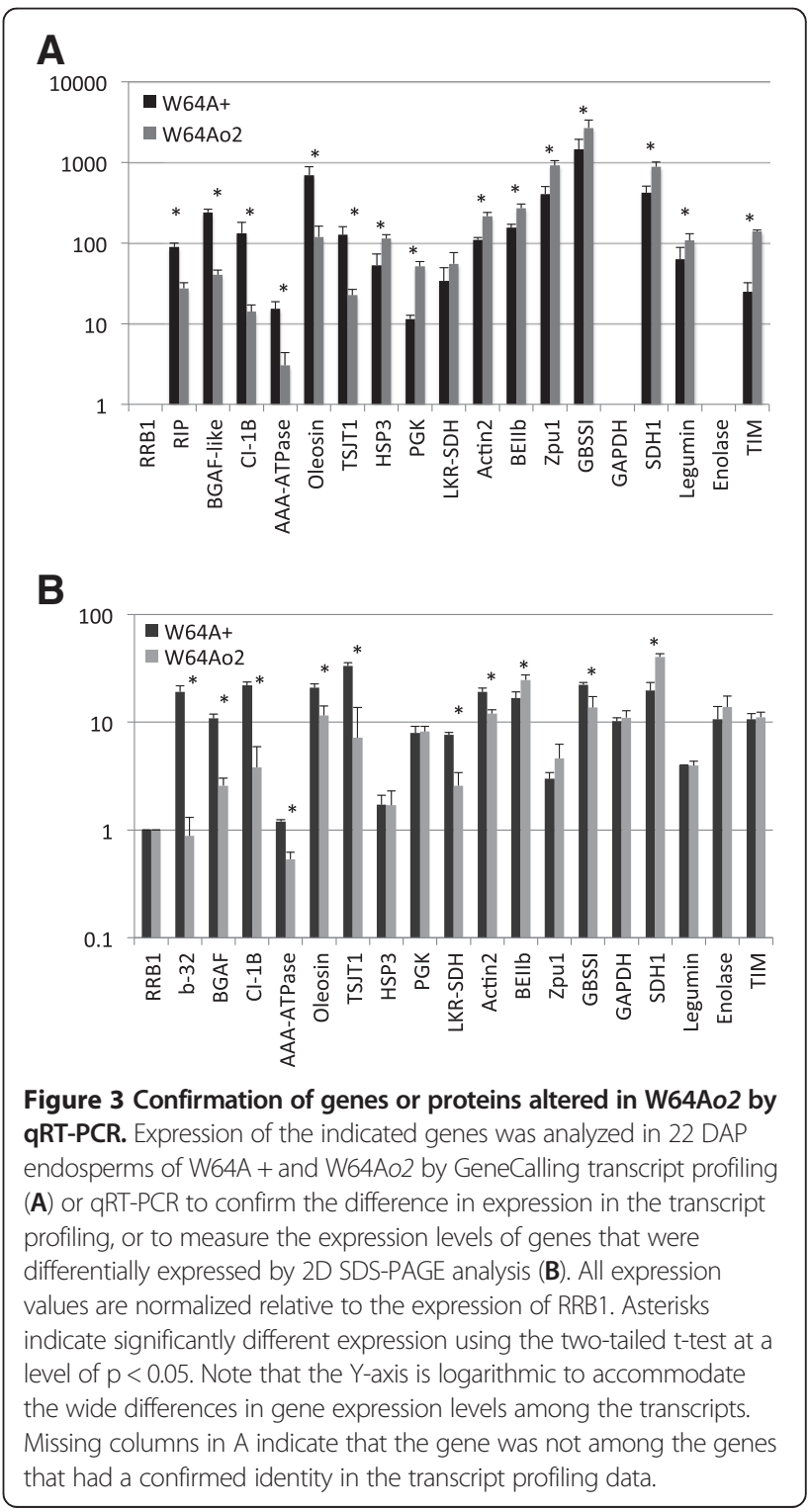


in gene expression are the result of the $o 2$ mutation, and not the genetic background or environmental conditions in the field. On the other hand, the expression of some genes was not consistent, notably LKR-SDH and GBSSI. As stated previously LKR-SDH was not significantly different in the transcript profiling data (Figure 3A), yet when measured by qRT-PCR in individuals grown in a different environment there was a significant difference (Figure 3B). Likewise, the difference in the transcript level of GBSSI was not consistent among previous reports [20-22]. GBSSI transcript increased in o2 according to the GeneCalling analysis, but decreased significantly based on the qRT-PCR analysis. These results together with data from prior studies indicate that expression of GBSSI and LKR-SDH may be dependent on both genotype and environmental conditions.

Carbohydrate metabolism-related genes significantly affected in $o 2$ by either GeneCalling or 2D SDS-PAGE analysis were also examined by qRT-PCR. Of the genes that were tested, only SDH1 showed significantly higher expression in $o 2$ at 22 DAP (Figure 3). Finally, the expression of HSP3 and actin2 measured by qRT-PCR did not agree with the GeneCalling results, but the decreased level of actin2 in $o 2$ was observed in other experiments [21,22]. There is a possibility that this difference was due to primer specificity, since both HSP and actin belong to multigene families and there are other family members that share significant sequence similarity. Therefore, multiple gene family members could be detected at the same time in qRT-PCR.

\section{Western blot analysis of opaque2 and wild type lines}

Western blot analysis of 22 DAP W64A + and W64Ao2 maize endosperm was performed to extend the transcript profiling and proteomic analysis (Figure 4); quantitative measurement by densitometry is shown in Table 2. In contrast to the gene expression data, the $o 2$ mutants showed an increase in GAPDH protein abundance by both 2D SDS-PAGE and by western blot analysis. This suggests that the GAPDH protein may be particularly stable in endosperm cells and therefore accumulates to a substantially higher level than indicated by its transcript abundance during seed development. Although expression of actin 2 was increased in $o 2$ in the transcript profiling data, no measurable protein difference was observed on western blots (Figure 4). However, the anti-actin antibody available is reported to recognize many isoforms of the protein across multiple kingdoms. Therefore it was not specific for the product of the gene that was up regulated in the present analysis. As expected, EF1A was significantly higher in o2, whereas other translation-related factors were either slightly higher (translation initiation factor 5A, IF5A) or slightly lower (ribosomal protein S6, S6RP) in W64Ao2.

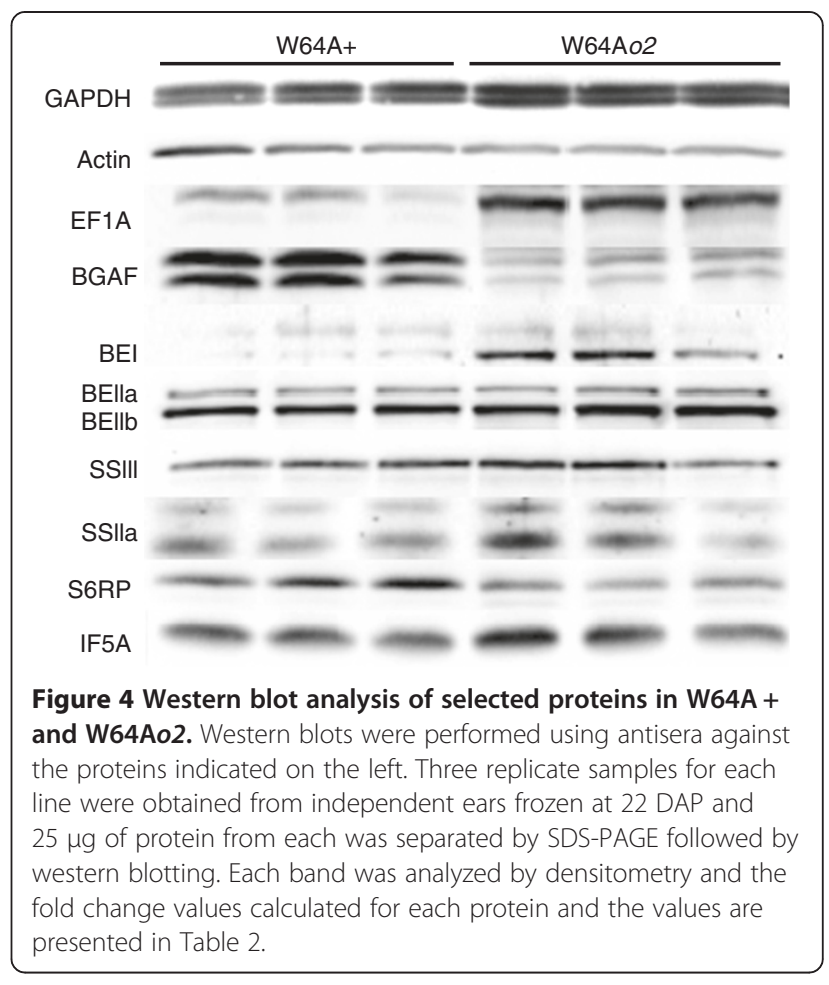

However, there were no measurable differences in eukaryotic translation initiation factor 4G (eIF4G), eukaryotic translation initiation factor 2 alpha subunit (eIF2 $\alpha$ ), or eukaryotic translation initiation factor $4 \mathrm{E}$ (eIF4E) (not shown). Analysis of starch biosynthetic enzymes showed that BEIIa and BEIIb were not different between 02 and wild type. However, there was increased accumulation of starch synthase IIa (SSIIa) and starch branching enzyme I (BEI) in $o 2$. Both of these enzymes

Table 2 Densitometry analysis of western blots of wild type and opaque 2 endosperm extracts

\begin{tabular}{|c|c|c|c|c|c|c|}
\hline \multicolumn{3}{|c|}{ W64A+ } & \multicolumn{2}{|c|}{ W64Ao2 } & \multirow[b]{2}{*}{ Fold-change } & \multirow[b]{2}{*}{$\mathrm{p}^{1}$} \\
\hline Protein & Mean & SD & Mean & SD & & \\
\hline GAPDH & 9.80 & 0.65 & 14.73 & 0.94 & 1.50 & 0.002 \\
\hline EF1A & 2.57 & 0.82 & 7.19 & 0.62 & 2.79 & 0.001 \\
\hline S6RP & 7.16 & 0.59 & 5.03 & 0.91 & -1.43 & 0.03 \\
\hline IF5A & 8.19 & 0.88 & 9.37 & 1.61 & 1.14 & 0.33 \\
\hline Actin & 2.84 & 0.78 & 2.47 & 0.23 & -1.15 & 0.47 \\
\hline BGAF & 7.55 & 1.62 & 2.23 & 0.38 & -3.38 & 0.005 \\
\hline SSIla & 2.68 & 0.43 & 3.74 & 0.87 & 1.40 & 0.13 \\
\hline SSIII & 5.22 & 0.79 & 6.35 & 0.84 & 1.22 & 0.17 \\
\hline BEl & 0.69 & 0.07 & 2.04 & 0.54 & 2.97 & 0.01 \\
\hline BElla & 3.08 & 0.17 & 3.74 & 0.67 & 1.21 & 0.18 \\
\hline BEllb & 5.83 & 0.64 & 7.52 & 1.02 & 1.29 & 0.07 \\
\hline
\end{tabular}

'p-value for two tailed Student's t-test. Bold figures are significantly different at a level of $p<0.05(n=3)$. 
have significant effects on starch structure when mutated or knocked down by RNAi, which results in the accumulation of amylopectin with relatively short glucan chains $[62,63]$. In contrast, BEI preferentially produced longer chain length branches (>16) compared with BEIIb, which preferentially produced shorter branches $(<12)$ in an in vitro assay [64]. Together, these observations suggest that in the W64Ao2 mutant the average chain length of amylopectin branches would be greater than in W64A + .

\section{Analysis of starch}

The expression of several starch biosynthesis genes varied between W64A + and W64Ao2 based on gene expression analysis and 2D SDS-PAGE. Interestingly, o2 was the only mutant among eight different isogenic opaque mutant lines that showed significant expression differences in starch biosynthesis genes ([22], Gibbon and Larkins unpublished). Because levels of several starch biosynthesis enzymes were altered in o2, SSIIa and BEI in particular, the properties of the starch from W64A + and W64Ao2 were analyzed by differential scanning calorimetry (DSC) to determine if these changes affected the starch structure. The onset and peak endotherm temperatures as well as the total enthalpy of gelatinization were significantly higher for W64Ao2 (Table 3). The higher values for these thermal properties in $o 2$ are consistent with starch that has longer amylopectin branches and higher crystalline starch content. To further characterize the structure of the starch, the amylopectin branch length distributions of W64A + and W64Ao2 were measured. Debranched starch glucans were separated by capillary electrophoresis and the resulting branch length distributions were compared (Figure 5). The two genotypes had similar molar percent content of glucans, but the distribution of glucans from W64Ao2 was shifted toward a higher degree of polymerization (Figure 5A). A difference plot clearly showed a marked increase in glucan chains with a degree of polymerization between 15 and 25 glucose subunits in W64Ao2 (Figure 5B). These results were similar to what was previously observed for 02 in the CM105 inbred line [49]. Together, the western blot analysis and analysis of starch structure suggest that enhanced BEI or SSIIa activity results in amylopectin with significantly longer glucan chains in W64Ao2. These changes in the crystallinity and branching pattern of

Table 3 DSC analysis of W64A + and W64A02 starch

\begin{tabular}{llll}
\hline & W64A+ & W64Ao2 & $\mathbf{p}^{\mathbf{1}}$ \\
\hline Onset $\left({ }^{\circ} \mathrm{C}\right)$ & $68.02 \pm 0.659$ & $71.38 \pm 0.169$ & $<.0001$ \\
Peak Endotherm $\left({ }^{\circ} \mathrm{C}\right)$ & $71.84 \pm 0.846$ & $74.65 \pm 0.172$ & $<.0001$ \\
Total Enthalpy $(\mathrm{J} / \mathrm{G})$ & $11.29 \pm 0.83$ & $14.39 \pm 1.00$ & $<.0001$ \\
\hline
\end{tabular}

${ }^{1}$ Student's t-test.
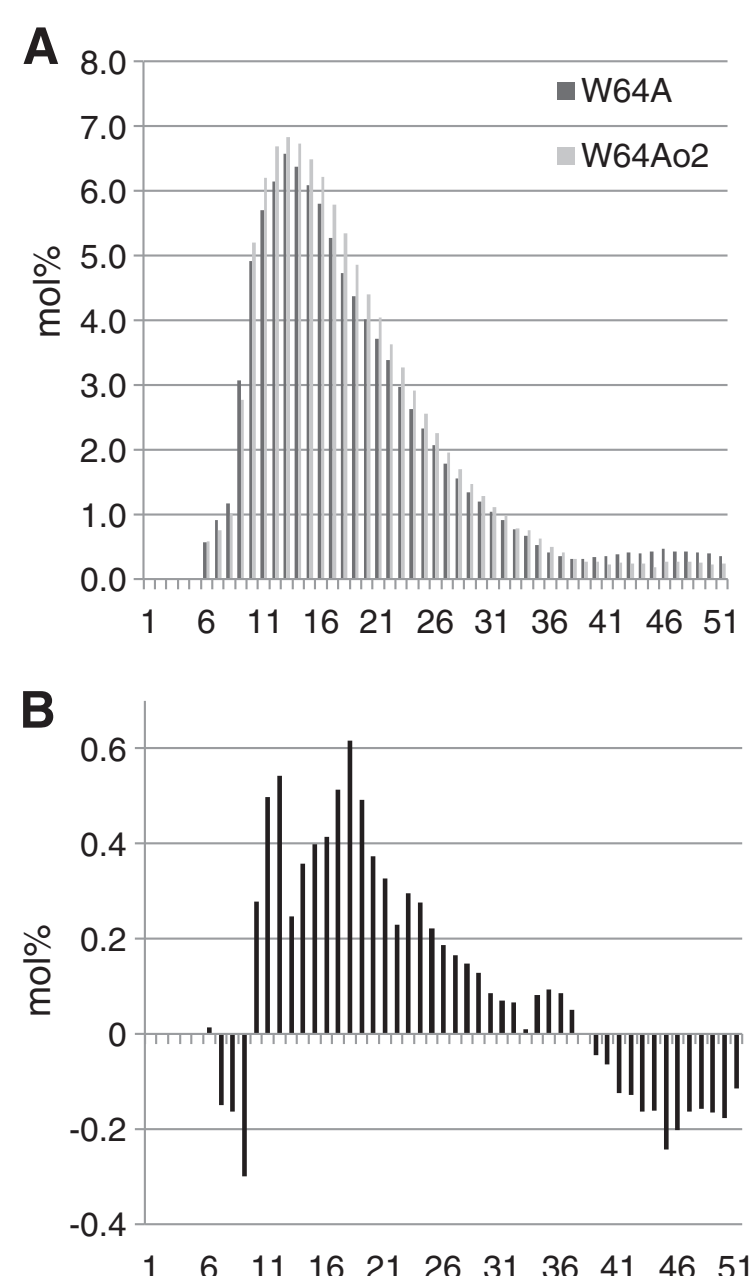

Figure 5 Amylopectin branch length analysis. Solubilized starch was de-branched in the presence of isoamylase and the resulting glucan chains were separated by capillary electrophoresis.

(A) Histograms of the distribution of glucan chains were similar but W64Ao2 was shifted toward a higher degree of polymerization. (B) Difference plot was calculated by subtracting the W64A + values from the W64Ao2 values showed a substantial increase in chains with a degree of polymerization between 15 and 25 glucose subunits. The histograms represent the average of three replicates for each genotype.

W64Ao2 starch may alter the association of the starch granules with endosperm proteins and thus promote formation of a soft, opaque phenotype.

\section{Conclusions}

The analysis of opaque 2 transcription patterns by Gene Calling significantly expanded the results of previous studies using microarrays, and by combining transcript profiling with proteomic analysis, we were able to document the presence of certain abundant lysine-containing proteins related to primary carbon metabolism. This is consistent with prior proteomic analyses of developing kernels [25], but the relative levels appear to be 
proportionally much higher in mature kernels. The two proteins that appeared to be most abundant were SDH1 and GAPDH, which have lysine contents of 4.2 and 8.5 percent, respectively. Especially for GAPDH, its relatively high accumulation in mature endosperm could contribute a substantial proportion of the total increased lysine observed in $o 2$. The results could explain the relatively high lysine content of W64Ao2 endosperm, and the basis of the phenotypic variability for this trait among maize inbreds [65].

Additional genes that contribute to the deleterious phenotypes of $o 2$ and that appear to be related to pest resistance were identified in this analysis. RIP is a wellknown 02 target gene and plays a role in the defense against fungal pathogenesis [66]. Likewise, BGAF was strongly down regulated, and it is suggested to have a role of concentrating beta-glucosidase at wound sites to promote activation of glycosylated defense compounds [31]. Other down regulated defense proteins included $\mathrm{Cl}-1 \mathrm{~B}, \mathrm{BAP} 2$, and defensin SD2. Down regulation of such defense proteins may synergistically contribute to the high susceptibility of $o 2$ to fungal and insect pests. Investigation of these genes in 02 or modified $o 2$ backgrounds may aid in the development of better performing high lysine maize lines.

Finally, $o 2$ was the only opaque mutant to show significant alteration of starch biosynthetic gene expression. In particular, the up regulation of BEI and/or SSIIa appears to explain the production of starch granules that are more highly crystalline in character, which could contribute to the opaque phenotype. Former studies indicated that an alteration in starch granule structure could be an important contributor to the restoration of vitreous endosperm by $o 2$ modifiers in QPM [49]. Our recent studies indicate that pullulanase activity is significantly higher in QPM and correlates well with the extent of endosperm modification, and this change is most likely due to a reduction in glucan chain length relative to soft $o 2$ mutants (Wu and Gibbon unpublished data). Therefore, manipulation of starch quality by transgenic means or naturally occurring alleles of BEI or SSIIa may be a way to enhance kernel quality and suppress the opaque phenotype for the improvement of QPM or other high lysine maize lines.

\section{Methods}

\section{Transcript profiling by GeneCalling ${ }^{\mathrm{TM}}$}

Plants of the nearly-isogenic maize (Zea mays L.) inbred lines W64A + and W64Ao2 [22] were grown in the summer of 1998 in field plots at the Pioneer Hi-Bred International genetic nursery in Johnston, IA. Well-filled ears of each inbred line were harvested $22 \mathrm{DAP}$ and immediately frozen in liquid nitrogen. To minimize the effect of biological variation between ears on the gene expression analysis, equal numbers of endosperms from the middle portion of three ears were pooled. Total RNA was isolated using the PUREscript kit (Gentra Systems, Inc., Minneapolis), and mRNA profiling was performed at Curagen (New Haven, CT) by GeneCalling ${ }^{\mathrm{TM}}$ [26]. In brief, cDNA was synthesized from three independently pooled W64A + and three independently pooled W64Ao2 endosperm samples (biological repetitions). Each of the six cDNA preparations was divided into three aliquots (technical repetitions) to provide nine repetitions per genotype for profiling analysis. Each cDNA aliquot was digested with 47 different combinations of restriction enzyme pairs. Fragments from each digest were ligated to adapters; the fragments were amplified with primers that have unique tags (biotin on one end, fluorescent marker at the other). Labeled fragments were purified using streptavidin beads and resolved by high-resolution gel electrophoresis to generate traces showing peaks whose position and height represented $M_{\mathrm{r}}$ and abundance of cDNA fragment(s), respectively. GeneCalling $^{\mathrm{TM}}$ software compiled a list of differentially abundant fragments and assigned a ranking (significance) to each detected difference. The software further searched a nucleic acid database for fragments with the same length and end sequences and predicted likely gene candidates. The identity of predicted fragments was confirmed by competitive amplification with an unlabeled gene-specific primer ("poisoning") or by cloning and sequencing the fragment [26]. A file containing the confirmed gene sequence tags is provided as Additional file 3.

\section{Confirmation of expression differences by quantitative real-time PCR \\ Plant materials}

W64A + and o2 kernels for quantitative polymerase chain reaction (qRT-PCR) and western blotting were grown in Elm Mott, TX during the summer of 2012. The kernels were harvested at 22 DAP and kept frozen at $-80^{\circ} \mathrm{C}$. Three ears of each genotype were used as three biological replicates. Six endosperms of each ear were dissected and ground to a fine powder in liquid nitrogen using a mortar and pestle. For RNA isolation, up to $0.1 \mathrm{~g}$ of the materials were used. For protein extraction, $50 \mathrm{mg}$ were weighed and homogenized in borate extraction buffer $(12.5 \mathrm{mM} \mathrm{NaBO}, 1 \%[\mathrm{w} / \mathrm{v}]$ sodium dodecyl sulfate and $2 \%[\mathrm{v} / \mathrm{v}] 2$-mercaptoethanol).

\section{RNA isolation, CDNA synthesis and qRT-PCR}

Total RNA was isolated from frozen endosperms using Purelink ${ }^{\mathrm{TM}}$ Plant RNA Reagent (Invitrogen, Carlsbad, CA) following the manufacturer's instructions. RNA samples were diluted to a final concentration of $\sim 100 \mathrm{ng} / \mu \mathrm{l}$ and quantified on a NanoDrop 
ND-1000 UV/Vis spectrophotometer (NanoDrop Technologies, Wilmington, DE), the purity of which was checked by the ratio of absorptions at $260 \mathrm{~nm}$ and $280 \mathrm{~nm}$ and all the samples had a ratio $\geq 2.0$. First-strand cDNA was synthesized from $1 \mu \mathrm{g}$ of RNA using qScript ${ }^{\mathrm{TM}} \mathrm{cDNA}$ SuperMix (Quanta Biosciences, Gaithersburg, MD) and subsequently diluted 10 -fold in water.

Primers for qRT-PCR were designed to amplify a 150-300 bp region of selected genes based on Primer3 Plus software (http://www.bioinformatics.nl/cgi-bin/ primer3plus/primer3plus.cgi). Primers were designed for a $62^{\circ} \mathrm{C}$ annealing temperature and to span exonexon junctions in order to control for genomic DNA contamination (Additional file 4: Table S2).

For gene expression analysis, qRT-PCR was performed in a 72-well rotor using the Corbett Rotor-Gene ${ }^{\mathrm{TM}} 3000$ (Qiagen, Velancia, CA). Each $20 \mu$ reaction contained $10 \mu$ l PerfeCTa ${ }^{\circledR}$ SYBR $^{\circledR}$ Green FastMix ${ }^{\circledR}$ (Quanta Biosciences, Gaithersburg, MD), $2.5 \mu \mathrm{l}$ 10-fold diluted cDNA or $1 \mu$ l plasmid standards with copy numbers from $10^{5}$ to $10^{8}$, and $1 \mu \mathrm{M}$ of each primer. The PCR program was as follows: $50^{\circ} \mathrm{C}$ hold for $2 \mathrm{~min}$ for auto gain optimization, $95^{\circ} \mathrm{C}$ initial denaturing for $10 \mathrm{~min}$, 50 cycles of $95^{\circ} \mathrm{C}$ for $15 \mathrm{~s}$ and $60^{\circ} \mathrm{C}$ for $1 \mathrm{~min}$. Melting curves were obtained by heating from $55^{\circ} \mathrm{C}$ to $95^{\circ} \mathrm{C}$ with a $1^{\circ} \mathrm{C}$ per second ramp rate to confirm single amplicons. Expression levels of genes in W64A + and W64Ao2 were normalized against the expression of RRB1 gene in the corresponding genotypes [67], since it was not differentially expressed between the two genotypes in preliminary experiments. Normalization of Gene expression was performed using the Q-Gene Core Module file [68]. Statistical differences of gene expression levels between W64A + and W64Ao2 were evaluated with unpaired two-tailed student's t-test, and the agreement of gene expression levels from transcript profiling and qRT-PCR results were calculated with Pearson correlation coefficient with significance determined by ANOVA, using the JMP statistical software (SAS Institute Inc., Cary, NC).

\section{Kernel protein extraction, SDS-PAGE and western blotting}

Total soluble proteins from maize kernels were extracted with borate extraction buffer containing $12.5 \mathrm{mM}$ sodium borate, 1\% (w/v) SDS, 2\% $\beta$-mercaptoethanol, pH 10 [69]. One $\mathrm{ml}$ of borate extraction buffer was added to $50 \mathrm{mg}$ ground kernels and incubated with shaking for at least $2 \mathrm{~h}$ at room temperature. Insoluble cell debris was removed from the crude extract by centrifugation for $15 \mathrm{~min}$ at $16,000 \times \mathrm{g}$ at room temperature. The cleared protein extracts were aliquoted and stored at $-80^{\circ} \mathrm{C}$.

Twenty-five $\mu \mathrm{g}$ of total protein from each sample were separated by $12 \%$ SDS-PAGE in $1 \mathrm{X}$ SDS-PAGE running buffer (25 mM Tris, $192 \mathrm{mM}$ glycine, 0.1\% (w/v) SDS) and then transferred to a BioTrace ${ }^{\mathrm{TM}}$ PVDF membrane
(Pall Corporation, Pensacola, FL) using a TE 22 Mighty Small Transphor Tank Transfer Unit (GE Healthcare, Piscataway, NJ). The quality of protein transfer was visually checked using pre-stained protein markers (Precision Plus Protein ${ }^{\mathrm{TM}}$ All Blue standards, Bio-Rad, Hercules, CA) and staining the membrane with Ponceau $\mathrm{S}(0.1 \%[\mathrm{w} / \mathrm{v}]$ in $5 \%[\mathrm{v} / \mathrm{v}]$ acetic acid). The membrane was blocked with $3 \%$ non-fat dry milk powder in $1 \mathrm{X}$ TBST buffer (10 mM Tris- $\mathrm{HCl}, \mathrm{Ph} 8.0,150 \mathrm{mM} \mathrm{NaCl}$, $0.1 \%(\mathrm{v} / \mathrm{v})$ Tween-20) for $1 \mathrm{~h}$ at room temperature with shaking.

Primary antibodies for immunoblots were as follows: RPS6 provided by Julia Bailey-Serres; BGAF provided by Asim Esen; GAPDH provided by Ming-Che Shih; eIF2 $\alpha$, eIF4E, and eIF4G provided by Karen Browning; SSIIa provided by Hanping Guan; SSIII, BEI and BEIIa/b provided by Alan Myers; anti-actin mouse monoclonal antibody (Cat. No. A0480, Sigma St. Lois MO). Membranes were incubated with primary antibodies diluted in TBST (1:1000 to $1: 3000$, based on the antibody titer) for $1 \mathrm{~h}$ at room temperature or overnight at $4^{\circ} \mathrm{C}$, washed with TBST and then incubated for $1 \mathrm{~h}$ at room temperature with secondary antibodies (horseradish peroxidase-conjugated goat anti-rabbit or goat anti-mouse; Invitrogen, Carlsbad, CA) diluted in TBST (1:30,000). After washing with TBST, the membrane was treated with $1 \mathrm{ml}$ SuperSignal West Pico Chemiluminescent Substrate (Pierce, Rockford, IL) for $2 \mathrm{~min}$ and the signals were detected using the UltraLUM Gel Imager System and UltraQuant 6.0 software (Ultra-Lum, Incorporated, Claremont, CA). The intensity of bands was quantified using the ImageJ software [70] and statistical differences of protein expression levels between W64A + and W64Ao2 were evaluated with unpaired two-tailed student's t-test with the JMP statistical software (SAS Institute Inc., Cary, NC).

\section{D SDS-PAGE}

Endosperms from mature kernels were isolated by soaking overnight in $\mathrm{dd}_{2} \mathrm{O}$ at $4^{\circ} \mathrm{C}$. Pericarp and embryo were removed and the endosperms dried in a freeze dryer; dried endosperms were ground to flour with a bead mill. Flour samples were extracted in borate extraction buffer with shaking overnight at $37^{\circ} \mathrm{C}$ [69]. Protein extracts were fractionated into zein and non-zein fractions by precipitation in $70 \%$ ethanol; the non-zein protein pellet was washed twice with $70 \%$ ethanol, dried and resuspended in IPG rehydration buffer (8 M urea, 2\% CHAPS, $20 \mathrm{mM}$ dithiothreitol, 0.005\% bromophenol blue). Samples were loaded into immobilized $\mathrm{pH}$ 4-7 gradient strips directly during the rehydration of the gel. The first dimension separation was performed according to the manufacturer's directions on either a Multiphor II or Ettan IPGphor 2 (GE Healthcare, Piscataway, NJ). The second dimension separation was performed using the 
Mini-Protein II vertical gel apparatus (Bio-Rad, Hercules, CA) according to the manufacturer's directions. Proteins were visualized with Coomassie brilliant blue. Gels were compared and spot intensities quantified using Prodigy SameSpots gel analysis software (Nonlinear Dynamics, Newcastle upon Tyne, UK).

\section{Protein identification}

Protein spots of interest were excised from the acrylamide gel and digested with trypsin using an in-gel digestion procedure. Briefly, gel pieces were destained by incubating in $50 \%$ acetonitrile $15 \mathrm{~min}$ at room temperature with two to three changes of solution. The gel pieces were dried in a Speed-Vac drier for $1 \mathrm{~h}$, and were rehydrated by incubating in trypsin digestion buffer (50 mM ammonium bicarbonate, $5 \mathrm{mM} \mathrm{CaCl}_{2}, 15 \mu \mathrm{g} / \mathrm{ml}$ sequencing grade trypsin (Sigma, St. Louis, MO)) for 10 minutes. Excess buffer was removed and enough trypsin-free digestion buffer was added to barely cover the gel pieces; the samples were then incubated overnight at $37^{\circ} \mathrm{C}$. The buffer solution was removed to a fresh tube and the gel pieces were washed two times by incubating in $50 \%$ acetonitrile with $1 \%$ formic acid for 5 minutes and combined with the original supernatant. Peptides were concentrated and de-salted using C-18 Zip-Tips (Milipore, Billerica, MA) according to the manufacturer's instructions.

Protein identification was performed by MALDI-TOF peptide mass mapping at the University of Arizona Mass Spectrometry facility. The peak lists derived from the mass spectra were searched against the Genbank nonredundant database updated 7/1/11 using the ProFound peptide mapping tool ([71]; http://prowl.rockefeller.edu/). Searches were performed using monoisotopic masses with the following parameters: taxonomy, other green plants; constant modification, iodoacetamide; Partial modification, methionine oxidation; mass tolerance, 200 ppm.

\section{Analysis of starch structure}

Starch granules were purified essentially as described by Gutierrez et al. [72]. Mature kernels were soaked in $0.5 \% \mathrm{Na}_{2} \mathrm{~S}_{2} \mathrm{O}_{5}$ at $50^{\circ} \mathrm{C}$ for $24 \mathrm{~h}$. The endosperm was dissected from the pericarp and germ, and ground lightly in a mortar. The sample was blended with $50 \mathrm{mM} \mathrm{NaCl}$ for $30 \mathrm{~s}$ and filtered through two layers of Miracloth (Calbiochem, San Diego, CA). The filtered material was extracted and pelleted by centrifugation five times in 1:4 toluene: $50 \mathrm{mM} \mathrm{NaCl}$, followed by extraction two times with acetone. The starch was dried for $48 \mathrm{~h}$ before use.

Dried starch was weighed and suspended in a 1:3 [w:v] slurry in deionized water. The slurry was sealed in hermetic pans for DSC. The sample pan was loaded into the DSC instrument (Q200, TA Instruments, New Castle, DE) sample pedestal and the reference pedestal held an empty hermetic pan. The sample was equilibrated at $35^{\circ} \mathrm{C}$ and then a DSC scan was performed from $35-95^{\circ} \mathrm{C}$ heating at $5^{\circ} \mathrm{C} / \mathrm{min}$. The onset temperature, peak endotherm and total enthalpy were calculated using the TA Universal Analysis 2000 software (TA Instruments, New Castle, DE).

Amylopectin glucan chain length distributions were determined by capillary electrophoresis. Starch was dissolved in DMSO by heating to $95^{\circ} \mathrm{C}$ for 15 minutes. A small sample of the dissolved starch was debranched by isoamylase (Megazyme, Wicklow, Ireland) and the resulting glucans were labeled with 8-amino-1,3,6-pyrenetrisulfonic acid in the presence of sodium cyanoborohidride. A sample of the labeling reaction was diluted and the fluroescently labeled glucan chains were separated and quantified by fluorescence-assisted capillary electrophoresis. Histograms of the percentage of area for each peak were plotted and compared.

\section{Additional files}

\begin{abstract}
Additional file 1: Table S1. Gene expression values for differentially expressed bands with confirmed sequences.

Additional file 2: Figure S1. Correlation analysis of qRT-PCR and transcript profiling gene expression values. To examine reproducibility for measurement of gene expression, the values for genes confirmed by qRT-PCR were plotted against the values measured by GeneCalling transcript profiling. A Pearson correlation analysis was performed $(r=0.80)$ and the statistical significance of the linear regression was tested by ANOVA $(p<0.001)$. The value of $b-32$ from qRT-PCR was determined as a significant outlier by Grubbs' test and therefore the fold-change values of b-32 from both tests were removed from the plot and regression analysis.
\end{abstract}

Additional file 3: Sequence tags used to determine gene identities. FastA formatted sequence text file. The sequences for each band that were confirmed by either competitive PCR or sequencing of the band were used to determine gene identitiy by searching the non-redundant genbank database using the basic local alignment and search tools BLASTN and BLASTX.

Additional file 4: Table S2. qRT-PCR primer sequences.

\section{Abbreviations}

AAA-ATPase: Proteosome regulatory subunit AAA-ATPase; AFLP: Amplified fragment length polymorphism; AGP: Arabinogalactan protein; BAP2: Basal layer antifungal protein2; BEl: Starch branching enzyme I; BElla: Starch branching enzyme Ila; BEllb: Starch branching enzyme IIb; BGAF: Betaglucosidase aggregating factor; $\mathrm{Cl}-1 \mathrm{~B}$ : Subtilisin-chymotrypsin inhibitor $\mathrm{Cl}-1 \mathrm{~B}$; DSC: Differential scanning calorimetry; DAP: Days after pollination; EF1A: Translation elongation factor 1 alpha; elF2a: Eukaryotic translation initiation factor 2 alpha subunit; elF4E: Eukaryotic translation initiation factor 4E; elF4G: Eukaryotic translation initiation factor 4G; ER: Endoplasmic reticulum; ERO1: ER Membrane-Localized Oxidoreductase 1;

GAPDH: glyceraldehyde-3-posphate dehydrogenase; N4: General control non-derepressible 4; GDSL: Glycine-aspartic acid-serine-leucine; GBSSI: Granule-bound starch synthase I; HSP3: 17.4-kDa Class I heat shock protein 3; IF5A: Translation initiation factor 5A; LKR-SDH1: Lysineketoglutarate reductase/saccharopine dehydrogenase1; MAPK: Mitogenactivated protein kinase; MEE21: Maternal effect embryo arrest 21; NAC: NAM, ATAF, and CUC transcription factor; 02: Opaque2; PDI: Protein disulfide isomerase; $\bar{P}$ GK: Cytosolic phosphoglycerate kinase; qRT-PCR: Quantitative real-time polymerase chain reaction; $\mathrm{RBOHB}$ : Respiratory burst oxidase protein homolog B; RIP: Ribosome-inactivating protein; RNAi: RNA interference; ROS: Reactive oxygen species; RRB1: Retinoblastoma-related 
protein 1; S6RP: Ribosomal protein S6; SDH1: Sorbitol dehydrogenase 1; SSIla: Starch synthase Ila; SSIII: Starch synthase III; TSJT1: Stem-specific protein; TA1: Tryptophan aminotransferase; TIM: Triose phosphate isomerase; Zpu1: Pullulanase-type starch debranching enzyme1.

\section{Competing interests}

The authors declare no competing interests.

\section{Authors' contributions}

MJ Experimental data and writing. KC Experimental data. HW Experimental data. RJ Experimental design and data. BAL Writing and experimental design. BCG Writing, experimental design and data. All authors read and approved the final manuscript.

\section{Acknowledgements}

We thank Asim Esen for the antisera against BGAF, Julia Bailey-Serres for antisera against ribosomal protein S6, Ming-Che Shih for antisera against GAPDH, Hanping Guan for antisera against SSIla, and Karen Browning for antisera against elF2a, elF4E and elF4G. We also thank Alan Myers for antisera against BEI, BEIla/b and SSIII, and Tracie Hennen-Bierwagen for performing capillary electrophoresis. This work was supported by USDA-NIFA grant 2010-65115-20375 and a Baylor University URSA award to BCG and a grant from Pioneer Hi-Bred to BAL. Portions of this work were made possible by the Baylor University Molecular Biosciences Center.

\section{Author details}

${ }^{1}$ Department of Biology, Baylor University, One Bear place \#97388, Waco, TX 76798, USA. ²Pioneer Hi-Bred International, Inc., Johnston, IA 50131, USA ${ }^{3}$ Department of Plant Sciences, University of Arizona, Tucson, AZ 85721, USA.

Received: 23 September 2012 Accepted: 5 April 2013

Published: 12 April 2013

\section{References}

1. Pingali PL: CIMMYT 1999-2001 Facts and Trends. Meeting world maize needs. Technological opportunities and priorities for the public sector. El Batán: CIMMYT; 2001.

2. Tester $M$, Langridge $P$ : Breeding technologies to increase crop production in a changing world. Science 2010, 327:818-822.

3. Mertz ET, Bates LS, Nelson OE: Mutant gene that changes protein composition and increases lysine content of maize endosperm. Science 1964, 145:279-280.

4. Nelson OE, Mertz ET, Bates LS: Second mutant gene affecting the amino acid pattern of maize endosperm proteins. Science 1965, 150:1469-1470.

5. Schoonhoven AV, Wassom CE, Horber E: Development of maize weevil on kernels of opaque-2 and floury-2, nearly isogenic corn inbred lines. Crop Sci 1972, 12:862-863.

6. Warren $\mathrm{HL}$ : Comparison of normal and high-lysine maize inbreds for resistance to kernel rot caused by fusarium-moniliforme. Phytopathology 1978, 68:1331-1335.

7. Schmidt RJ, Burr FA, Aukerman MJ, Burr B: Maize regulatory gene opaque2 encodes a protein with a leucine-zipper motif that binds to zein DNA. Proc Natl Acad Sci USA 1990, 87:46-50.

8. Schmidt RJ, Ketudat M, Aukerman MJ, Hoschek G: Opaque-2 is a transcriptional activator that recognizes a specific target site in $22-\mathrm{Kd}$ -zein genes. Plant Cell 1992, 4:689-700.

9. Mertz ET, Veron OA, Bates LS, Nelson OE: Growth of rats Fed on opaque-2 maize. Science 1965, 148:1741-1742.

10. Vasal SK, Villegas E, Bjarnason M, Gelaw B, Goertz P: Genetic modifiers and breeding strategies in developing hard endosperm opaque 2 materials. In Improvement of quality traits of maize for grain and silage. Edited by Pollmer WG, Phillips RH. London: Nijhoff; 1980:37-73.

11. Huang S, Frizzi A, Florida CA, Kruger DE, Luethy MH: High lysine and high tryptophan transgenic maize resulting from the reduction of both 19- and 22-kD alpha-zeins. Plant Mol Biol 2006, 61:525-535.

12. Huang SS, Kruger DE, Frizzi A, D'Ordine RL, Florida CA, Adams WR, Brown WE, Luethy MH: High-lysine corn produced by the combination of enhanced lysine biosynthesis and reduced zein accumulation. Plant Biotechnol J 2005, 3:555-569.

13. Segal G, Song RT, Messing J: A new opaque variant of maize by a single dominant RNA-interference-inducing transgene. Genetics 2003, 165:387-397.
14. Scrimshaw NS: Quality protein maize. Food Nutr Bull 2006, 27:265-266.

15. Vivek BS, Krivanek AF, Palacios-Rojas N, Twumasi-Afriyie S, Diallo AO: Breeding quality protein maize (QPM): protocols for developing QPM cultivars. Mexico, D.F: CIMMYT; 2008

16. Hournard NM, Mainville JL, Bonin CP, Huang S, Luethy MH, Malvar TM: High-lysine corn generated by endosperm-specific suppression of lysine catabolism using RNAi. Plant Biotechnol J 2007, 5:605-614.

17. Wu YR, Messing J: RNA interference Can rebalance the nitrogen sink of maize seeds without losing hard endosperm. PLoS One 2012, 7:e32850.

18. Gutierrez-Rojas A, Scott MP, Leyva OR, Menz M, Betran J: Phenotypic characterization of quality protein maize endosperm modification and amino acid contents in a segregating recombinant inbred population. Crop Sci 2008, 48:1714-1722.

19. Schmidt MA, Herman EM: Proteome rebalancing in soybean seeds can be exploited to enhance foreign protein accumulation. Plant Biotechnol J 2008, 6:832-842

20. Frizzi A, Caldo RA, Morrell JA, Wang M, Lutfiyya LL, Brown WE, Malvar TM, Huang S: Compositional and transcriptional analyses of reduced zein kernels derived from the opaque2 mutation and RNAi suppression. Plant Mol Biol 2010, 73:569-585.

21. Hartings $H$, Lauria M, Lazzaroni N, Pirona R, Motto M: The Zea mays mutants opaque- 2 and opaque-7 disclose extensive changes in endosperm metabolism as revealed by protein, amino acid, and transcriptome-wide analyses. BMC Genomics 2011, 12:41.

22. Hunter BG, Beatty MK, Singletary GW, Hamaker BR, Dilkes BP, Larkins BA, Jung R: Maize opaque endosperm mutations create extensive changes in patterns of gene expression. Plant Cell 2002, 14:2591-2612.

23. Jia H, Nettleton D, Peterson JM, Vazquez-Carrillo G, Jannink JL, Scott MP. Comparison of transcript profiles in wild-type and 02 maize endosperm in different genetic backgrounds. Crop Sci 2007, 47:S45-S59.

24. Frizzi A, Huang S, Gilbertson LA, Armstrong TA, Luethy MH, Malvar TM: Modifying lysine biosynthesis and catabolism in corn with a single bifunctional expression. Plant Biotechnol J 2008, 6:13-21.

25. Damerval C, Le Guilloux M: Characterization of novel proteins affected by the 02 mutation and expressed during maize endosperm development. Mol Gen Genet 1998, 257:354-361.

26. Shimkets RA, Lowe DG, Tai JT, Sehl P, Jin H, Yang R, Predki PF, Rothberg BE, Murtha MT, Roth ME, et al: Gene expression analysis by transcript profiling coupled to a gene database query. Nat Biotechnol 1999, 17:798-803

27. Song RT, Llaca V, Linton E, Messing J: Sequence, regulation, and evolution of the maize 22-kD alpha zein in gene family. Genome Res 2001, 11:1817-1825

28. Song RT, Messing J: Contiguous genomic DNA sequence comprising the 19-kD zein gene family from maize. Plant Physiol 2002, 130:1626-1635.

29. Hey TD, Hartley M, Walsh TA: Maize ribosome-inactivating protein (b-32). Homologs in related species, effects on maize ribosomes, and modulation of activity by pro-peptide deletions. Plant Physiol 1995, 107:1323-1332.

30. Bass HW, Webster C, Obrian GR, Roberts JKM, Boston RS: A maize ribosome-inactivating protein is controlled by the transcriptional activator opaque-2. Plant Cell 1992, 4:225-234

31. Blanchard DJ, Cicek M, Chen J, Esen A: Identification of beta-glucosidase aggregating factor (BGAF) and mapping of BGAF binding regions on Maize beta -glucosidase. J Biol Chem 2001, 276:11895-11901.

32. Kittur FS, Lalgondar M, Yu HY, Bevan DR, Esen A: Maize beta-glucosidase -aggregating factor is a polyspecific jacalin-related chimeric lectin, and its lectin domain is responsible for beta-glucosidase aggregation. J Biol Chem 2007, 282:7299-7311.

33. Yunes JA, Vettore AL, da Silva MJ, Leite A, Arruda P: Cooperative DNA binding and sequence discrimination by the Opaque2 bZIP factor. Plant Cell 1998, 10:1941-1955.

34. Habib HaF KM: Plant protease inhibitors: a defense strategy in plants. Biotechnol Mol Biol Rev 2007, 2:68-85.

35. Ganz T: Defensins: antimicrobial peptides of innate immunity. Nat Rev Immunol 2003, 3:710-720.

36. Olsen AN, Ernst HA, Lo Leggio L, Skriver K: NAC transcription factors: structurally distinct, functionally diverse. Trends Plant Sci 2005, 10:79-87.

37. Durner J, Knorzer OC, Boger P: Ketol-Acid Reductoisomerase from Barley (Hordeum vulgare) (Purification, Properties, and Specific Inhibition). Plant Physiol 1993, 103:903-910 
38. Kemper EL, Neto GC, Papes F, Moraes KCM, Leite A, Arruda P: The role of Opaque 2 in the control of lysine-degrading activities in developing maize endosperm. Plant Cell 1999, 11:1981-1993.

39. Hinnebusch AG: The general control of amino acid biosynthetic genes in the yeast Saccharomyces cerevisiae. CRC Crit Rev Biochem 1986, 21:277-317.

40. Mauri I, Maddaloni M, Lohmer S, Motto M, Salamini F, Thompson R, Martegani E: Functional expression of the transcriptional activator opaque-2 of Zea mays in transformed yeast. Mol Gen Genet 1993, 241:319-326.

41. Nakamura M, Ehrhardt DW, Hashimoto T: Microtubule and katanindependent dynamics of microtubule nucleation complexes in the acentrosomal Arabidopsis cortical array. Nat Cell Biol 2010, 12:1064-1070.

42. Panteris E, Adamakis IDS, Voulgari G, Papadopoulou G: A role for katanin in plant cell division: microtubule organization in dividing root cells of fra2 and lue1 arabidopsis thaliana mutants. Cytoskeleton 2011, 68:401-413.

43. Showalter AM: Arabinogalactan-proteins: structure, expression and function. Cell Mol Life Sci 2001, 58:1399-1417.

44. Clouse SD, Sasse JM: BRASSINOSTEROIDS: essential regulators of plant growth and development. Annu Rev Plant Physiol Plant Mol Biol 1998, 49:427-451

45. Pagnussat GC, Yu HJ, Ngo QA, Rajani S, Mayalagu S, Johnson CS, Capron A Xie LF, Ye D, Sundaresan V: Genetic and molecular identification of genes required for female gametophyte development and function in Arabidopsis. Development 2005, 132:603-614.

46. Rolletschek H, Koch K, Wobus U, Borisjuk L: Positional cues for the starch/ lipid balance in maize kernels and resource partitioning to the embryo. Plant J 2005, 42:69-83.

47. Eastmond PJ, van Dijken AJ, Spielman M, Kerr A, Tissier AF, Dickinson HG, Jones JD, Smeekens SC, Graham IA: Trehalose-6-phosphate synthase 1, which catalyses the first step in trehalose synthesis, is essential for Arabidopsis embryo maturation. Plant J 2002, 29:225-235.

48. Grennan AK: The role of trehalose biosynthesis in plants. Plant Physiol 2007, 144:3-5

49. Gibbon BC, Wang X, Larkins BA: Altered starch structure is associated with endosperm modification in Quality Protein Maize. Proc Natl Acad Sci USA 2003, 100:15329-15334.

50. Onda Y, Kumamaru T, Kawagoe Y: ER membrane-localized oxidoreductase Ero1 is required for disulfide bond formation in the rice endosperm. Proc Natl Acad Sci USA 2009, 106:14156-14161.

51. Kuettner EB, Hilgenfeld R, Weiss MS: Purification, characterization, and crystallization of alliinase from garlic. Arch Biochem Biophys 2002, 402:192-200.

52. Martinez M, Cambra I, Carrillo L, Diaz-Mendoza M, Diaz I: Characterization of the entire cystatin gene family in barley and their target cathepsin Llike cysteine-proteases, partners in the hordein mobilization during seed germination. Plant Physiol 2009, 151:1531-1545.

53. Igawa T, Ochiai-Fukuda T, Takahashi-Ando N, Ohsato S, Shibata T, Yamaguchi I, Kimura M: New TAXI-type xylanase inhibitor genes are inducible by pathogens and wounding in hexaploid wheat. Plant Cell Physiol 2004, 45:1347-1360.

54. Oh IS, Park AR, Bae MS, Kwon SJ, Kim YS, Lee JE, Kang NY, Lee SM, Cheong $\mathrm{H}$, Park OK: Secretome analysis reveals an Arabidopsis lipase involved in defense against Alternaria brassicicola. Plant Cell 2005, 17:2832-2847.

55. Vierling E: The roles of heat-shock proteins in plants. Annu Rev Plant Physiol Plant Mol Biol 1991, 42:579-620.

56. Mukatira UT, Liu CM, Varadarajan DK, Raghothama KG: Negative regulation of phosphate starvation-induced genes. Plant Physiol 2001, 127:1854-1862.

57. Moons A, Bauw G, Prinsen E, Vanmontagu M, Vanderstraeten D: Molecular and physiological responses to abscisic acid and salts in roots of salt-sensitive and salt-tolerant Indica rice varieties. Plant Physiol 1995, 107:177-186.

58. Asai S, Ohta K, Yoshioka H: MAPK signaling regulates nitric oxide and NADPH oxidase-dependent oxidative bursts in Nicotiana benthamiana. Plant Cell 2008, 20:1390-1406.

59. Pandey SP, Somssich IE: The role of WRKY transcription factors in plant immunity. Plant Physiol 2009, 150:1648-1655.

60. Lending CR, Larkins BA: Changes in the zein composition of protein bodies during maize endosperm development. Plant Cell 1989, 1:1011-1023.

61. Habben JE, Moro GL, Hunter BG, Hamaker BR, Larkins BA: Elongation factor 1 alpha concentration is highly correlated with the lysine content of maize endosperm. Proc Natl Acad Sci USA 1995, 92:8640-8644.
62. Nakamura Y: Towards a better understanding of the metabolic system for amylopectin biosynthesis in plants: Rice endosperm as a model tissue. Plant Cell Physiol 2002, 43:718-725.

63. Zhang XL, Colleoni C, Ratushna V, Sirghle-Colleoni M, James MG, Myers AM: Molecular characterization demonstrates that the Zea mays gene sugary2 codes for the starch synthase isoform SSlla. Plant Mol Biol 2004, 54:865-879.

64. Guan HP, Li P, ImparlRadosevich J, Preiss J, Keeling P: Comparing the properties of Escherichia coli branching enzyme and maize branching enzyme. Arch Biochem Biophys 1997, 342:92-98.

65. Moro GL, Habben JE, Hamaker BR, Larkins BA: Characterization of the variability in lysine content for normal and opaque2 maize endosperm. Crop Sci 1996, 36:1651-1659.

66. Ferreira RB, Monteiro S, Freitas R, Santos CN, Chen Z, Batista LM, Duarte J, Borges A, Teixeira AR: The role of plant defence proteins in fungal pathogenesis. Mol Plant Pathol 2007, 8:677-700.

67. Sabelli PA, Dante RA, Leiva-Neto JT, Jung R, Gordon-Kamm WJ, Larkins BA RBR3, a member of the retinoblastoma-related family from maize, is regulated by the RBR1/E2F pathway. Proc Natl Acad Sci USA 2005, 102:13005-13012.

68. Simon P: Q-Gene: processing quantitative real-time RT-PCR data. Bioinformatics 2003, 19:1439-1440.

69. Wallace JC, Lopes MA, Paiva E, Larkins BA: New methods for extraction and quantitation of zeins reveal a high content of gamma-zein in modified opaque-2 maize. Plant Physiol 1990, 92:191-196.

70. Schneider CA, Rasband WS, Eliceiri KW: NIH Image to ImageJ: 25 years of image analysis. Nat Methods 2012, 9:671-675.

71. Zhang W, Chait BT: ProFound: an expert system for protein identification using mass spectrometric peptide mapping information. Anal Chem 2000, 72:2482-2489.

72. Gutierrez OA, Campbell MR, Glover DV: Starch particle volume in single- and double-mutant maize endosperm genotypes involving the soft starch (h) gene. Crop Sci 2002, 42:355-359.

doi:10.1186/1471-2229-13-60

Cite this article as: Jia et al:: Identification and characterization of lysinerich proteins and starch biosynthesis genes in the opaque2 mutant by transcriptional and proteomic analysis. BMC Plant Biology 2013 13:60.

\section{Submit your next manuscript to BioMed Central and take full advantage of:}

- Convenient online submission

- Thorough peer review

- No space constraints or color figure charges

- Immediate publication on acceptance

- Inclusion in PubMed, CAS, Scopus and Google Scholar

- Research which is freely available for redistribution

Submit your manuscript at www.biomedcentral.com/submit
C Biomed Central 